\title{
Performance of Cluster Bean (Cyamopsis Tetragonoloba L.Taub.) Genotypes under different Environmental Conditions
}

\author{
P. Satyavathi* and M. Vanaja \\ Matrusri Engineering College, Saidabad, Hyderabad- 500059, India
}

\begin{abstract}
Cluster bean (Cyamopsis tetragonoloba L.Taub.), called as guar, is an important commercial crop which is grown both in arid and semi-arid region. Cluster bean is a drought resistant annual legume crop. Being a leguminous crop, it fixes the atmospheric nitrogen and enriches the soil fertility. Owing to the significant application of guar gum in industries like pharmaceuticals, cosmetics, mining, textile, paper, oil drilling, shale gas industry etc., identification of suitable cluster bean genotypes for semi-arid regions is need of the hour. Field studies were conducted with five cluster bean genotypes RGC-1017, RGC-936, RGC-986, RGC-1025 and HGS365 during three different seasons $(S)$ in order to expose their critical growth stages at different temperatures and quantified the impacts on growth and yield. The crop experienced maximum temperatures of $32.2^{\circ} \mathrm{C}, 39.4^{\circ} \mathrm{C}$ and $43.8^{\circ} \mathrm{C}$ during S1, S2 and S3. All the morphological, biomass and yield parameters were highly significant for genotypes, seasons and their interaction. The seasonal impact on five genotypes differed with vegetative and reproductive components. Among the three seasons, all the genotypes registered lower biomass and seed yield during S1 as the temperatures are lower than $35^{\circ} \mathrm{C}$. Among the genotypes, RGC-936, RGC-986 recorded highest total biomass and seed yield during S2 while the genotypes RGC-1017 and HGS-365 during S3 whereas genotype RGC-1025 recorded its highest biomass during S2 while seed yield during S3. The variation between genotypes for biomass and seed yield was high during S1 and S3 while minimum during S2, indicating that when temperatures are below $35^{\circ} \mathrm{C}$ or more than $40^{\circ} \mathrm{C}$, the selection of suitable genotype is necessary. This clearly revealed that the environment influenced the individual genotype performance in terms of biomass and yield.
\end{abstract}

Key words: Cluster bean, genotypes, seasons, temperature, yield

\section{Introduction}

Guar is an important leguminous annual crop also called as "cluster bean" (Cyamopsis tetragonoloba L.) for its pattern of pod arrangements in clusters is a summer/rainy season legume crop. It is believed to be native of India and Pakistan where it is grown mainly for green fodder, pods and seeds. The area, production and yield of the crop in India are inconsistent due to its over dependence on weather and production confined to limited geographical area largely arid regions of Rajasthan and parts of Gujarat, Haryana and Punjab. The green tender pods consumed as green vegetable are rich source of Vitamin A and C and iron. Guar crop has experienced an incredible journey from a traditional crop grown mainly for food, animal feed and fodder to a crop with various industrial usages ranging from food, paper, textile, oil drilling, mining, explosives, ore flotation etc. The unique binding, thickening and emulsifying property of guar gum powder obtained from guar seed has made it a much sought after product in international market. The United State of America is the largest importer of Guar and its derivatives from India. Guar gum, also called guaran, is a galactomannan. The guar seeds are dehusked, milled and screened to obtain the guar gum. There is a necessity for developing expanse and season based guar crop production techniques with optimum use of inputs to increase economic returns. The Indian arid zone characterized by deficient moisture and nutrient, and high sunlight provides optimum agro-climatic conditions for the successful cultivation of cluster bean, as the crop is known for high adaption towards poor and erratic 
rain, for its need of little surface water, abundant sunshine and low relative humidity during the cropping season [1].

\section{Materials and Methods}

Field experiments with 5 genotypes of cluster bean- RGC-1017, RGC-936, RGC-986, RGC-1025, HGS-365 were conducted during three seasons in order to assess the impact of seasons on performance of different morphological, biomass and yield traits. The germplasm was obtained from Rajasthan Seed Corporation and raised at CRIDA (HRF), Hyderabad and evaluated during different seasons; Season1: S1 (01-08-2013 to 25-102013), Season2 (S2) (12-2-2014 to 19-5-2014) and Season3 (S3) (6-5-2015 to 1-8-2015). The selected genotypes were sown in $2.25 \mathrm{~m} \times 2.0 \mathrm{~m}$ plots maintaining $15 \mathrm{~cm}$ space between plants and $45 \mathrm{~cm}$ between rows with three replications. The crop was maintained moisture and nutrient stress free by irrigating at regular intervals and applying recommended dose of fertilizers. During the crop growth period the crop experienced maximum, minimum and average temperatures of $32.2^{\circ} \mathrm{C}, 16.5^{\circ} \mathrm{C}$ and $25.11^{\circ} \mathrm{C}$ during $\mathrm{S} 1 ; 39.5^{\circ} \mathrm{C}, 14^{\circ} \mathrm{C}$ and $27.61^{\circ} \mathrm{C}$ during S2; and $43.8^{\circ} \mathrm{C}, 21.5^{\circ} \mathrm{C}, 30.34^{\circ} \mathrm{C}$ during S3.

The growth, biomass and yield potentials were quantified at the time of harvest. The plants were harvested at maturity and five representative plant samples of each genotype were randomly chosen to determine the morphological, biomass and yield characters. The plants were uprooted and the roots were washed carefully in order to remove the soil adhere to them and separated to record root volume and root biomass. The plants were separated into stem, leaves and pods. The harvested plant parts, viz. roots, stem, leaves and husk were dried at $60^{\circ} \mathrm{C}$ till constant weights were attained to determine the respective components of biomass. Observations were recorded at harvest on a) eight morphological traits viz., (i) plant height (cm); (ii) stem girth (mm); (iii) number of leaves; (iv) number of branches; (v) root length (cm); (vi) root volume (ml); (vii) number of clusters and (viii) number of pods; b) five biomass traits viz., (ix) leaf dry weight (g/plant) (x) stem dry weight (g/plant); (xi) root dry weight (g/plant); (xii) pod weight (g/plant); (xiii) total biomass (g/plant); c) three yield traits, viz., (xiv) seed yield (g/plant); (xv) test weight (g); (xvi) harvest index (\%) under each season. The total biomass and HI were derived from the recorded observations. The data was statistically analyzed using a two-way analysis of variance (ANOVA) to test the significance of genotypes, seasons and their interactions.

\section{Results and Discussion}

Based on ANOVA, it was observed that all the morphological traits, biomass traits and yield parameterswere highly significant $(\mathrm{p}<0.01)$ for genotypes, seasons and their interaction except number of branches (Table 1).

\section{Performance of Morphological Traits}

Plant height is influenced by the interaction of environmental conditions and genetic constitution of the plant. All the selected five cluster bean genotypes recorded highest plant height during S3 when compared with $\mathrm{S} 1$ and S2, however the magnitude of response differed with genotypes (Fig.1). Among the three seasons, the maximum mean plant height was recorded during $S 3(72.28 \mathrm{~cm})$ period, while the mean plant height was similar in $\mathrm{S} 1$ and $\mathrm{S} 2(64.14 \mathrm{~cm}$ and $64.72 \mathrm{~cm})$. Among the cluster bean genotypes, the maximum plant height was recorded with HGS-365 $(83.20 \mathrm{~cm})$ during S3, while RGC-936 $(46.40 \mathrm{~cm})$ recorded the minimum plant height. The genotype RGC-986 could maintain similar plant height in all the three seasons ( $\mathrm{S} 1-65.62 \mathrm{~cm} ; \mathrm{S} 2-64.20 \mathrm{~cm}$; $\mathrm{S} 3-65.40 \mathrm{~cm}$ ). In the present study the minimum and maximum temperatures were recorded higher during S3 than S1 and S2 from the date of sowing to flowering period and it might have hastened the growth processes and improved the plant height. Satyavathi et al. [2] reported that cluster bean plant height was maximum during warm period than cool period. 
Maximum mean stem girth was registered during S3 $(8.51 \mathrm{~mm})$ and minimum in S2 $(4.67 \mathrm{~mm})$, however the variation was minimum in S2. The genotype HGS-365 recorded highest stem girth (10.06mm) during S3 recorded lowest $(4.16 \mathrm{~mm})$ in S2 (Fig.1). Among the seasons, the genotypes RGC-1017 (7.82mm) and RGC-936 (7.20mm) registered similar stem girth, while RGC-986 and HGS-365 recorded maximum stem girth in S3 while HGS-365 in S2. Similar response of maximum stem girth of cluster bean genotypes was recorded at higher temperatures during summer [3] Girish et al. [4] also reported positive and significant correlation of plant height with stem girth in cluster bean genotypes.

The mean performance of genotypes for number of leaves at the time of harvest was maximum during S2 whereas lowest in S1(Fig.1). The genotypic variability for number of leaves was low during S2 while it was high at S3. The genotype HGS-365 recorded lowest number of leaves during S2 and it was able to retain highest leaf number during S3. The highest leaf number in all the three seasons was registered by HGS-365. All the genotypes in S1 and the genotypes RGC-936 and RGC-1025 in S3 recorded only senesced leaves at harvest. Deka et al. [5] also revealed that cluster bean crop sowing on 1st July produced maximum number of branches under agro climatic conditions of Assam.

There was a significant variation for number of branches among the genotypes and seasons. Maximum number of branches was recorded in S2 (11.60) and minimum in S1 (2.20). The genotype RGC-986 showed stable performance for number of branches as well as for plant height across the three seasons (Fig.1). The genotype HGS-365 was able to record highest plant height and number of branches in S3 and could maintain it in S2 while recorded lowest at S1. This clearly indicating that this trait response to environmental condition is significant and variability among genotypes was also significant. Rajasekar et al. [6] also recorded the reduction of number of branches, inter-nodal length and plant height in winter grown cluster bean when compared with summer performance. Mid-June planting of guar recorded more number of branches than late-July planting [7].

All the cluster bean genotypes showed higher root length during S3 as compared with S1 and S2. The genotype HGS-365 recorded highest root length during all the seasons (Fig.1). The genotypes RGC-1017, RGC936, RGC-986, and RGC-1025 recorded minimum variability for root length at S3. As the upper layer of the soil tends to dry at higher temperatures in S3, plants tend to produce longer roots to extract the soil moisture from the deeper layers. Ghazi et al. [8] observed difference in root length with varied temperatures in barley. Similarly, increased root length at higher temperature was also observed in cluster bean [2], in urdbean [9], while Batts et al. [10] also observed decreased root growth with temperature stress during reproductive development, due to decreased partitioning to roots. There was a significant variation for root volume among the genotypes and seasons. Maximum mean root volume was recorded during S3 and minimum in S2 (Fig.1). All the genotypes in S3 registered highest root length and also registered maximum root volume. The genotypic variability was high in S1 while it was low in S2 and S3. The genotype HGS-365 registered highest root volume in S3, while RGC986 in S1 and S2. It is evident from the results that the belowground parts such as root length as well as root volume are also influenced by the environmental conditions which in turn affected the plant performance during different seasons.

Number of clusters per plant of cluster bean varied significantly among the genotypes and seasons. Among all the seasons, highest number of clusters was recorded in S2 and lowest in S1. The genotype HGS-365 recorded maximum number of clusters in S2 and S3, while RGC-986 recorded maximum in S1.The genotypic variability for number of clusters was low in S1 and S2, while it was high in S3. All the genotypes in S2 recorded maximum number of clusters incidentally during this season the genotypes also produced maximum number branches. Warmer growing conditions and more rainfall under mid-June planting produced more number of clusters in cluster bean genotypes [7] and positive and significant correlation for number of clusters per plant was reported [4].

There was significant impact of seasons for per plant pod number of cluster bean genotypes. Maximum mean number of pods was registered in S2 (106/pl), followed by S3 (88.84/pl) and S1 (49.96/pl). In S2, the variability within genotypes for number of pods was low while it was high in S1 and S3. The genotype HGS-365 
registered maximum number of pods in S3 while it was lowest in S2. Similarly the genotype RGC-936 recorded highest pod number in S2 while it was lowest in S1. This clearly indicates that suitability of environmental conditions of individual genotype for pod number varied significantly. Increased plant height, stem girth, number of branches and number of leaves plays a crucial role in increasing the pod number. The observations revealed that the higher temperature $\left(>40^{\circ} \mathrm{C}\right)$ during S3 helped in promoting morphological traits whereas moderate temperatures of $\mathrm{S} 2\left(<40^{\circ} \mathrm{C}\right)$ are promoting reproductive components.

\section{Biomass Parameters}

All the cluster bean genotypes showed significant variation for leaf biomass at harvest with seasons. All the genotypes in S2 recorded maximum number of leaves and could record maximum leaf biomass (Fig. 2). There was complete shedding of leaves with RGC-936 and RGC-1025 during S3. The maximum leaf biomass was registered by HGS-365 in S3 and moderate values in S1 and S2. While the genotype RGC-986 recorded maximum leaf weight in S1 and S2. Among all the seasons the genotype HGS-365 recorded highest plant height, number of branches, number of leaves and highest leaf biomass. Being a dual purpose crop, the retention of green leaves at harvest improves its fodder value. Hence the genotypes with better leaf biomass at harvest will be preferred by arid/ semiarid farmers.

Significant variation among the genotypes and seasonal impact was observed for stem biomass. Among the seasons, the mean performance of genotypes was similar and highest during S3 and S2 whereas lowest in S1(Fig. 2). The genotypic variability for stem biomass was low during S2 while it was high at S1 and S3. The genotype RGC-986 was stable across the seasons with minimum variation in stem biomass.

The seasonal impact on different genotypes was minimal for mean root biomass of cluster bean genotypes. Among the seasons the maximum mean root biomass was registered in S3 (1.78g/pl) followed by S2 (1.22g/pl) and minimum in S1 $(0.84 \mathrm{~g} / \mathrm{pl})$. The genotype HGS-365 recorded maximum root length, root volume and could also register maximum root biomass in S3 (Fig. 2). Among the genotypes, RGC 986 could maintain better root biomass in all the three seasons with less variability. Increased root lengths at higher temperature recorded the higher root biomass in S3.

Pod dry matter is the most important indicator of achieving the better seed yield. There was significant impact of seasons on the pod weight of cluster bean genotypes. Among the three seasons, the maximum pod weight was registered in $\mathrm{S} 3(30.54 \mathrm{~g} / \mathrm{pl})$ and minimum in $\mathrm{S} 1(12.34 \mathrm{~g} / \mathrm{pl})$. The genotype HGS-365 could register maximum number of pods in S3 was also recorded more pod weight (Fig. 2). Increased pod weight in cluster beans at higher temperatures was reported [6] and Panotra et al. [11] reported that different genotypes and different planting dates significantly influenced the pod weight per plant of blackgram.

Dry matter accumulation and distribution is an important factor indicating partitioning efficiency of photosynthetic assimilates. During S3, total biomass and fodder biomass was maximum and followed by S2 and S1 (Fig. 2). Variability among genotypes was maximum in S1 and minimum in S2 and S3. The seasonal impact of total biomass of different genotypes was mainly influenced by the pod weight response. Kalyani [12] recorded significant variation in total biomass of guar in different planting dates. Among all the seasons, maximum fodder biomass was recorded by HGS-365 in S3 and S1, by RGC-936 in S2.

\section{Yield Parameters}

All the cluster bean genotypes showed significant variation in per plant seed weight with different seasons. The mean performance of the genotypes was high in S3 and low in S1(Fig. 2). The genotypic variability for seed weight was low in S2, while high in S1 and S3. The highest seed weight was recorded by HGS-365 (30.64g/pl) in S3, by RGC-936 (15.03g/pl) in S2 and RGC-986 $(9.64 \mathrm{~g} / \mathrm{pl})$ in $\mathrm{S} 1$. Mid-May planting of cluster bean genotypes produced the maximum seed yield in Mediterranean environment of Italy [13]. 
The genotype RGC-1017 registered highest test weight in S3 and S1, though it could not record higher seed yield revealing the effective seed filling capability of this genotype. Similarly the genotype RGC-1025 registered higher test weight in S2 (Fig. 2). Among all the seasons the mean test weight was lowest with majority of the genotypes in $\mathrm{S} 1$ as during this season the plant growth, biomass and reproductive components performance was poor and the environmental conditions not supported even seed filling.

A significant variation in $\mathrm{HI}$ was observed among the genotypes and seasons. The mean performance of genotypes for HI was similar during S1 and S3 whereas it was recorded highest in S2 (Fig. 2). The genotypic variability for HI was low during S1 and S2, while it was registered high in S3. The highest HI was recorded with RGC-1025 in S3; while HGS-365 in S2; and RGC-1017 in S1. It is clearly reflecting that the influence of seasons varied with biomass and seed yield, though both biomass and seed yield was low during S1, it recorded better HI as compared with S3, this is due to low impact of environmental conditions of S1 on yield. Similarly, during S2 both biomass and seed yield recorded high and proportioning of biomass to yield components was also better which resulted in higher HI. Vijaylaxmi [14] reported that high temperature conditions during late sowing had reduced the harvest index in pea while increased the HI of cluster bean genotypes [2].

\section{Acknowledgements}

The present work is part of Ph.D. thesis work of PS and we acknowledge the Director, CRIDA for providing facilities and Management of Matrusri Engineering College for permissions.

\section{References}

[1] Pathak R, and Roy MM. Climatic responses, environmental indices and interrelationships between qualitative and quantitative traits in cluster bean under arid condition. Proceedings of the National Academy of Sciences, India Section $B$ (Biological Science) vol. 85 (1), pp. 147-154, 2015

https://doi.org/10.1007/s40011-013-0269-4

[2] Satyavathi P, Vanaja M, Vagheera P, Vijaykumar G, Sathish P and Ira Khan. Genotypic variability and seasonal impact on biomass and yield performance of cluster bean. International Journal for Current Sciences, vol. 20(3), pp. E 1-9, 2017.

[3] Satyavathi P, Vanaja M, Gopala Krishna Reddy A, Vagheera P, Narasimha Reddy A, Vijaykumar G, Razak Abdul, Vaidya Sunitha, Sowmya P, and Ira Khan. Identification of Suitable Guar Genotypes for Summer Season of Semi-Arid Region. International Journal of Applied Biology and Pharmaceutical Technology. vol. 5(4), pp. 71-73, 2014.

[4] Girish M. H, Gasti V. D, Mastiholi A. B, Thammaiah N, Shantappa T, Mulge R and Kerutagi M. G. Correlation and path analysis for growth, pod yield, seed yield and quality characters in cluster bean (Cyamopsis tetragonoloba (L.) Taub.). Karnataka Journal of Agricultural Science, vol. 25 (4), pp. 498-502, 2012.

[5] Deka K.K, Das Milu R, Bora P and Mazumder N. Effect of sowing dates and spacing on growth and yield of cluster bean (Cyamopsis tetragonoloba) in subtropical climate of Assam, India. Indian Journal of Agricultural Research, vol. 49 (3) pp. 250-254, 2015. https://doi.org/10.5958/0976-058X.2015.00039.6

[6] [6] Rajasekar M, Arumugam T, and Ramesh Kumar S. Influence of weather and growing environment on vegetable growth and yield. Journal of Horticultural and Forestry, vol. 5(10), pp. 160-167, 2013

[7] Singla S, Grover K, Angadi SV, Begna SH, Schutte B, and Van Leeuwen D. Growth and yield of guar (Cyamopsis tetragonoloba L.) genotypes under different planting dates in the semi-arid southern high plains. American Journal of Plant Sciences, vol. 7, pp. 1246-1258, 2016 https://doi.org/10.1017/S0021859697005017

[8] Ghazi N, Karaki A, Al-Ajam A, Othman Y. Seed germination and early root growth of three Barely cultivars as affected by temperature and water stress. American-Eurasian Journal of Agricultural and Environmental Sciences, vol. 2, pp. 112-117, 2007. 
[9] Mahavir Singh, Rana, N.S, Panwar, G.S, Adesh Singh, and Dhyani B.P. Growth and yield behaviour of urdbean genotypes (Vigna mungo L.) under different dates of woeing and effect on soil health, Agriways, vol.1(2), pp. 83-89, 2013.

[10] Batts GR, Ellis RH, Morison JIL, Nkemka PN, Gregory PJ, and Hadley P. Yield and partitioning of crops of contrasting cultivars of winter wheat in tunnels. Journal of Agricultural Science, vol. 130, pp.17-27, 1998.

https://doi.org/10.1017/S0021859697005017

[11] Panotra N, Kumar A, and Singh OP. Effect of varieties and dates of sowing on growth parameters, yield attributes and yield of blackgram (Vigna mungo L.). International Journal of Scientific Engineering and Technology, vol. 5, pp. 38213826, 2016.

[12] Kalyani, D.L. Performance of Cluster Bean Genotypes under varied Time of Sowing. Legume Research, vol. 35, pp.154-158, 2012.

[13] Gresta F, Sortino O, Santonoceto C, Issi L, Formantici C and Galante Y. Effects of Sowing Times on Seed Yield, Protein and Galactomannans Content of Four Varieties of Guar (Cyamopsis tetragonoloba L.) in a Mediterranean Environment. Industrial Crops and Products, vol. 41, pp. 46-52, 2013.

https://doi.org/10.1016/j.indcrop.2012.04.007

[14] Vijaylaxmi. Effect of high temperature on growth, biomass and yield of field pea genotypes. Legume Research, vol. 36, 250-254, 2013.

TABLE 1. ANOVA of Morphological, Biomass and Yield Parameters of Five Guar Genotypes During Three Seasons

\begin{tabular}{|c|c|c|c|c|c|}
\hline \multirow[t]{2}{*}{ Parameter } & \multicolumn{3}{|c|}{ Mean sum of squares } & \multirow[t]{2}{*}{$\mathrm{CV} \%$} & \multirow[t]{2}{*}{ Error } \\
\hline & Genotypes & Seasons & $\mathrm{G} \times \mathrm{S}$ & & \\
\hline \multicolumn{6}{|c|}{ Morphological Characters } \\
\hline Plant Height & $1824.313^{* *}$ & $984.714 * *$ & $2570.041 * *$ & 1.82 & 1.485 \\
\hline Stem Girth & $7.304 * *$ & $94.696 * *$ & $3.097 * *$ & 12.90 & 0.683 \\
\hline No. of Leaves & $2280.453^{* *}$ & $22048.37 * *$ & $3525.773 * *$ & 3.01 & 0.768 \\
\hline No. of Branches & $1.380 \mathrm{NS}$ & $216.893 * *$ & $15.710 * *$ & 15.43 & 1.370 \\
\hline Root Length & $14.148 * *$ & $25.173 * *$ & $4.687 * *$ & 10.31 & 1.266 \\
\hline Root Volume & $15.232 * *$ & $139.500^{* *}$ & $7.405 * *$ & 24.65 & 0.922 \\
\hline No. of Clusters & $215.153 * *$ & $4337.773^{* *}$ & $96.773 * *$ & 4.62 & 1.560 \\
\hline No. of Pods & $5005.100^{* *}$ & $20610.84^{* *}$ & $5824.440 * *$ & 3.94 & 10.360 \\
\hline \multicolumn{6}{|c|}{ Biomass Parameters } \\
\hline Leaf Weight & $33.129 * *$ & $39.616 * *$ & $20.606^{* *}$ & 13.82 & 0.141 \\
\hline Stem Weight & $92.684 * *$ & $450.724 * *$ & $87.630 * *$ & 13.95 & 1.661 \\
\hline Root Weight & $1.342 * *$ & $6.428 * *$ & $0.859 * *$ & 28.80 & 0.134 \\
\hline Pod Weight & $696.603 * *$ & $2220.323^{* *}$ & $582.586 * *$ & 4.98 & 1.294 \\
\hline Total Biomass & $1466.141^{* *}$ & $5495.641 * *$ & $1414.746^{* *}$ & 5.05 & 3.311 \\
\hline \multicolumn{6}{|c|}{ Yield Parameters } \\
\hline Seed Weight & $68.661 * *$ & $510.944 * *$ & $106.478 * *$ & 19.65 & 5.540 \\
\hline Test Weight & $0.221 * *$ & $1.381 * *$ & $0.164 * *$ & 3.55 & 0.013 \\
\hline Harvest Index & $92.171 * *$ & $125.116^{* *}$ & $83.217 * *$ & 17.84 & 42.375 \\
\hline
\end{tabular}

(** Significance at $1 \%$ level, * at $5 \%$ level) 

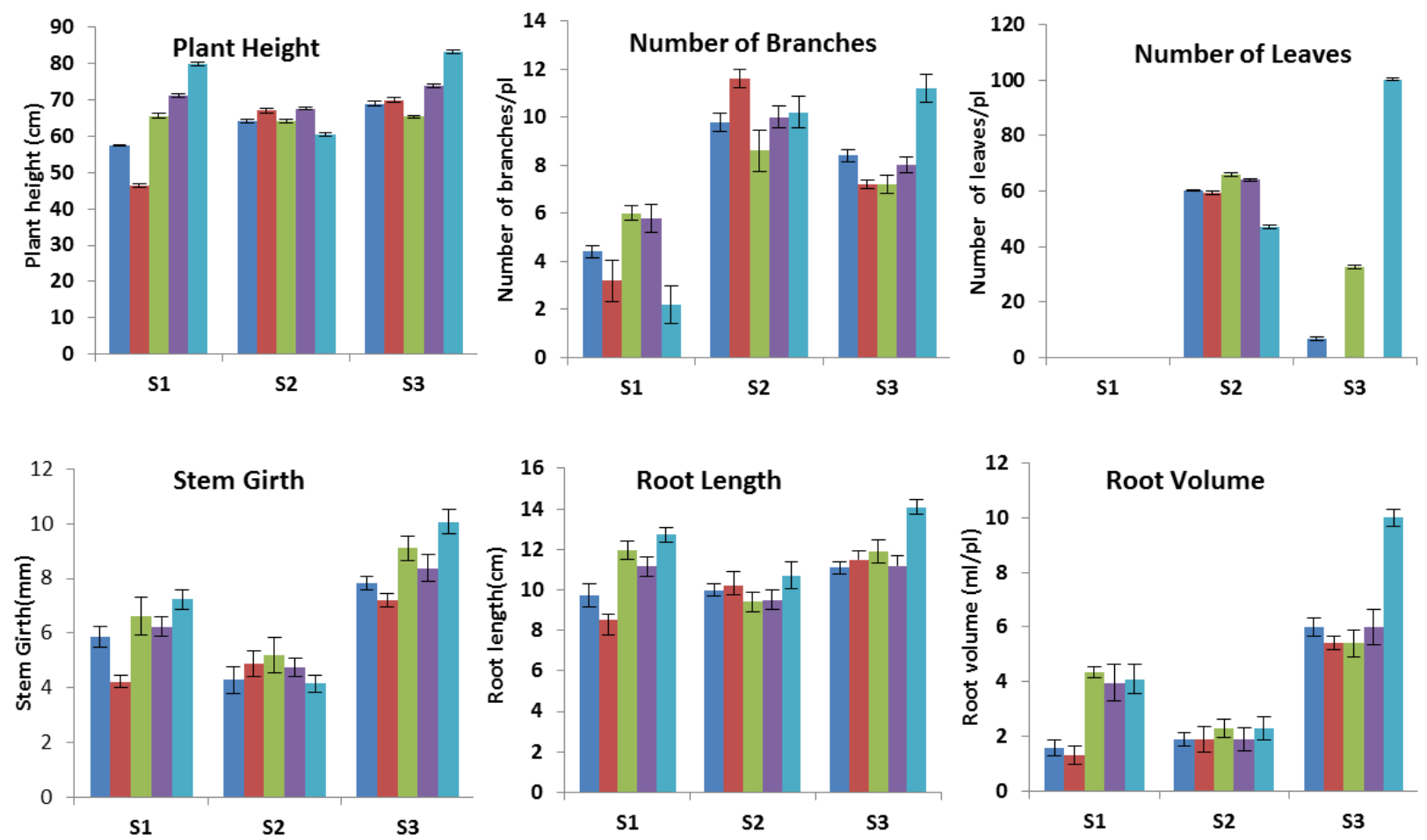

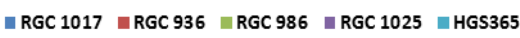

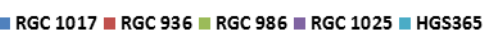

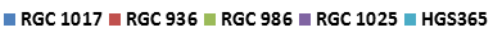

Fig. 1. Morphological parameters of five cluster bean genotypes during three seasons 

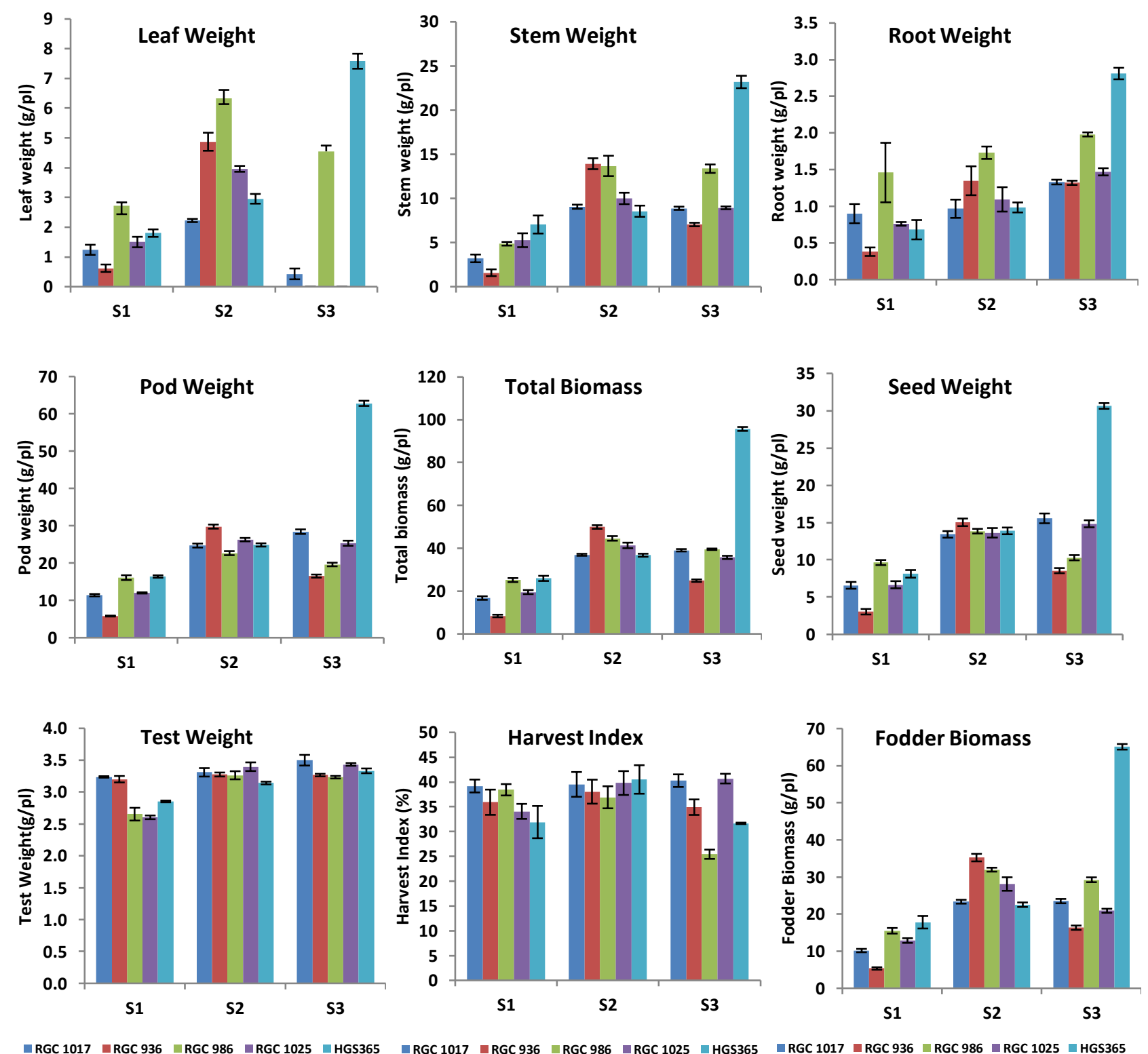

Fig. 2. Biomass and yield parameters of five cluster bean genotypes during three seasons 